\title{
Creatina como recurso ergogênico nutricional: uma revisão da literatura
}

Creatine as an ergogenic nutritional resource: a literature review

\section{Elton Bicalho de Souza}

Centro Universitário de Volta Redonda

elton.bicalho01@gmail.com

\section{Márcio Henrique Valin Silva}

UNIFOA 


\section{RESUMO}

A creatina é uma substância produzida naturalmente pelo corpo e encontrada em alimentos de origem animal. É considerada um recurso ergogênico nutricional efetivo para aumento do desempenho e ganho de massa muscular. 0 presente estudo teve como objetivo descrever os principais mecanismos de ação da creatina, apresentando as doses recomendadas de suplementação, tempo de uso, possíveis efeitos colaterais e para quais tipos de exercícios a suplementação é recomendada. Trata-se de uma revisão narrativa da literatura que foi realizado a partir de publicações científicas em português e inglês oriundas das bases de dados PubMed ${ }^{\circledR}, \mathrm{SciElo}^{\circledR}$ e Google Acadêmico ${ }^{\circledR}$. Os estudos selecionados apontaram que a suplementação de creatina entre 3 a 5 gramas por dia pode proporcionar um aumento no volume de água nas células musculares, aumento de síntese proteica, aumento na expressão gênica de IGF-1 e o aumento de fatores miogênicos regulatórios, além de atuar em uma das vias metabólicas de fornecimento e reposição de energia, possibilitando aumento do rendimento no treino (principalmente naqueles de alta intensidade e curta duração) e aumento do ganho de massa muscular. A suplementação de creatina demonstra-se segura para indivíduos saudáveis, sendo válido ressaltar a importância do acompanhamento profissional para adequação das dosagens de acordo com as necessidades.

Palavras-Chave: Creatina, Substâncias para melhoria do desempenho, Exercício físico

\section{ABSTRACT}

Creatine is a substance produced naturally by the body and found in foods of animal origin. It's considered an effective nutritional ergogenic resource to increase performance and gain muscle mass. This study aimed to describe the main mechanisms of action of creatine, presenting the recommended doses of supplementation, time of use, possible side effects and for which types of exercises supplementation is recommended. This is a narrative literature review that was carried out from scientific publications in Portuguese and English from the PubMed $\circledast$, SciElo $®$ and Google Academic $®$ databases. The selected studies showed that creatine supplementation between 3 to 5 grams per day can provide an increase in water volume in muscle cells, increased protein synthesis, increased gene expression of IGF-1 and increased regulatory myogenic factors, in addition to act in one of the metabolic pathways of energy supply and replacement, enabling increased training performance (especially in those of high intensity and short duration) and increased muscle mass gain. Creatine supplementation proves to be safe for healthy individuals, and it is worth emphasizing the importance of professional monitoring to adjust dosages according to needs.

Keywords: Creatine, Performance-enhancing substances, Exercise 


\section{INTRODUÇÃO}

A creatina (CR) - ou ácido a-metil guanidino acético, é uma amina nitrogenada formada por três aminoácidos: glicina, arginina e metionina. Pode ser formada a partir da síntese endógena (aproximadamente 1 grama) realizada no fígado, rins e pâncreas, ou pode ser obtida por meio da alimentação, uma vez que a está presente em alimentos como a carne vermelha e peixe, por exemplo, ou pela utilização de suplementos industrializados (Gualano et al., 2010).

0 início da formação da CR é nos rins, por meio de uma reação de desaminação e transaminação entre a arginina e glicina, catalisada pela enzima glicina-amina transaminase, formando guanidinoacetato e ornitina. A partir disso, já no fígado, o guanidinoacetato é metilado pela S-adenosil-metionina por meio da enzima guanidinoacetato N-metiltransferase, completando a síntese da CR (MENDES; TIRAPEGUI, 2002). Seu armazenamento no organismo humano concentra-se basicamente na musculatura esquelética (95\%) - na forma de creatina livre (40\%) e o restante na forma de fosfocreatina (CP), e também no cérebro, fígado, rins e testículos. A CP serve como um reservatório de energia nas células musculares e, durante a prática de exercício intenso, a sua participação é primordial para fornecimento rápido de trifosfato de adenosina (ATP) - por até 10 segundos (Febbraio et al., 1995; Gualano et al., 2010).

Evidências apontam que os níveis de CR podem afetar a transcrição gênica. Gualano et al. (2010) descrevem que dez dias de suplementação contínua de CR promovem elevação de inúmeros genes responsáveis pela regulação osmótica, síntese e degradação de glicogênio, remodelagem do citoesqueleto, proliferação e diferenciação de células satélites, reparo e replicação de ácido desoxirribonucleico (DNA), controle da transcrição de ácido ribonucleico (RNA) e morte celular. Outra importante função da CR está no estímulo da síntese proteica, pois é possível que o aumento da ingestão de CR possa influenciar na expressão gênica de fatores de crescimento semelhantes a insulina do tipo 1 (IGF-1) muscular, que ativa uma via de sinalização da proteína alvo da rapamicina em mamíferos (mTOR), a via de fosfoinositídeo-3-quinase-proteína quinase B / Akt (PI3KAKT/PKB), além das expressões gênicas proteicas e fosforilada. Ainda segundo Gualano et al. (2010) a expressão gênica de IGF-1 permanece aumentada durante o repouso realizados após exercícios de força, o que sugere a possibilidade da CR agir aumentando a hipertrofia e atenuando a atrofia, já que o IGF-1 exerce controle das vias tróficas.

Devido a sua importância, a comercialização da forma industrializada (suplemento) da CR aumentou consideravelmente, sendo utilizada com frequência não só por atletas, mas também por praticantes de exercício, pois possui efeitos ergogênicos comprovados pela literatura (Naderi et al., 2016). Entretanto, é importante o entendimento de suas vias metabólicas, bem como a quantidade recomendada e os tipos de exercícios em que a 
creatina possui boa correlação com desfechos positivos. Diante do exposto, a presente pesquisa objetivou descrever os principais mecanismos de ação da creatina, apresentando as doses recomendadas de suplementação, tempo de uso, possíveis efeitos colaterais e para quais tipos de exercícios a suplementação é recomendada.

\section{MÉTODOS}

A presente revisão narrativa da literatura foi realizada a partir de publicações científicas em português e inglês oriundas das bases de dados PubMed ${ }^{\circledR}$, SciElo ${ }^{\circledR}$ e Google Acadêmico ${ }^{\circledR}$, utilizando os descritores "suplementos nutricionais" or "dietary supplements", "creatina" or "creatine" e "exercício físico" or "exercise". Por conta da relevância do tema e dada a evolução ocorrida nos últimos anos acerca do tema optouse por não utilizar como critério de inclusão o ano de publicação das obras, nem os desenhos dos estudos pesquisados.

\section{REVISÃO DE LITERATURA}

\section{Creatina}

A CR é um composto formado por carbono, oxigênio, hidrogênio e nitrogênio, sintetizada a partir de dois aminoácidos não essenciais (arginina e glicina) e um aminoácido essencial (metionina). De acordo com Persky, Brazeau e Hochhaus (2003) os estoques intracelulares totais são de aproximadamente $120-125 \mathrm{mmol} / \mathrm{kg}$ de peso muscular, sendo constituídos tanto por síntese endógena quanto pela alimentação. Por estar presente em maior quantidade nos músculos, a CR é encontrada em grandes quantidades apenas em produtos de origem animal (Gomes; Tirapegui, 2000). 0 quadro 1 apresenta as principais fontes alimentares de creatina.

Quadro 1. Principais fontes alimentares de creatina

\begin{tabular}{ll}
\hline Alimento & Concentração de creatina $\mathbf{( g / k g )}$ \\
\hline Carne Suína & 5,0 \\
\hline Carne Bovina & 4,5 \\
\hline Arenque & $6,5-10,0$ \\
\hline Salmão & 4,5 \\
\hline Atum & 4,0 \\
\hline Bacalhau & 4,0
\end{tabular}


No Brasil, a suplementação de CR foi regulamentada pela Agência Nacional de Vigilância Sanitária (ANVISA) pela Resolução 18/2010, que no artigo 10 descreve que que a creatina deve atender aos seguintes requisitos mínimos para comercialização: "o produto pronto para consumo deve conter de 1,5 a $3 \mathrm{~g}$ de creatina na porção; deve ser utilizada na formulação do produto creatina monohidratada com grau de pureza mínima de 99,9\%; pode ser adicionado de carboidratos e não pode ser adicionado de fibras alimentares" (Brasil, 2010).

\section{Metabolismo}

Nos rins a formação da CR ocorre a partir de uma reação que envolve os aminoácidos arginina e glicina, com a desaminação da arginina para a transaminação da glicina, formando guanidinoacetato e ornitina, catalisada pela enzima glicina-amina transaminase (AGAT). No fígado, o guanidinoacetato é metilado pela S-adenosil-metionina por meio da enzima guanidinoacetato $\mathrm{N}$-metiltransferase (GAMT), formando a CR, distribuída pela corrente sanguínea. Já a $C R$ ingerida é absorvida de forma intacta pelo intestino e distribuída para os principais sítios de absorção (Mendes; Tirapegui, 2002). A Figura 1 ilustra o processo de síntese da creatina.

Figura 1. Nos rins a formação da CR ocorre a partir de uma reação que envolve os aminoácidos arginina e glicina, com a desaminação da arginina para a transaminação da glicina, formando guanidinoacetato (GAA) e ornitina, catalisada pela enzima glicina-amina transaminase (AGAT). No fígado, o guanidinoacetato (GAA) é metilado pela S-adenosil-metionina por meio da enzima guanidinoacetato N-metiltransferase (GAMT), formando a CR, distribuída pela corrente sanguínea.

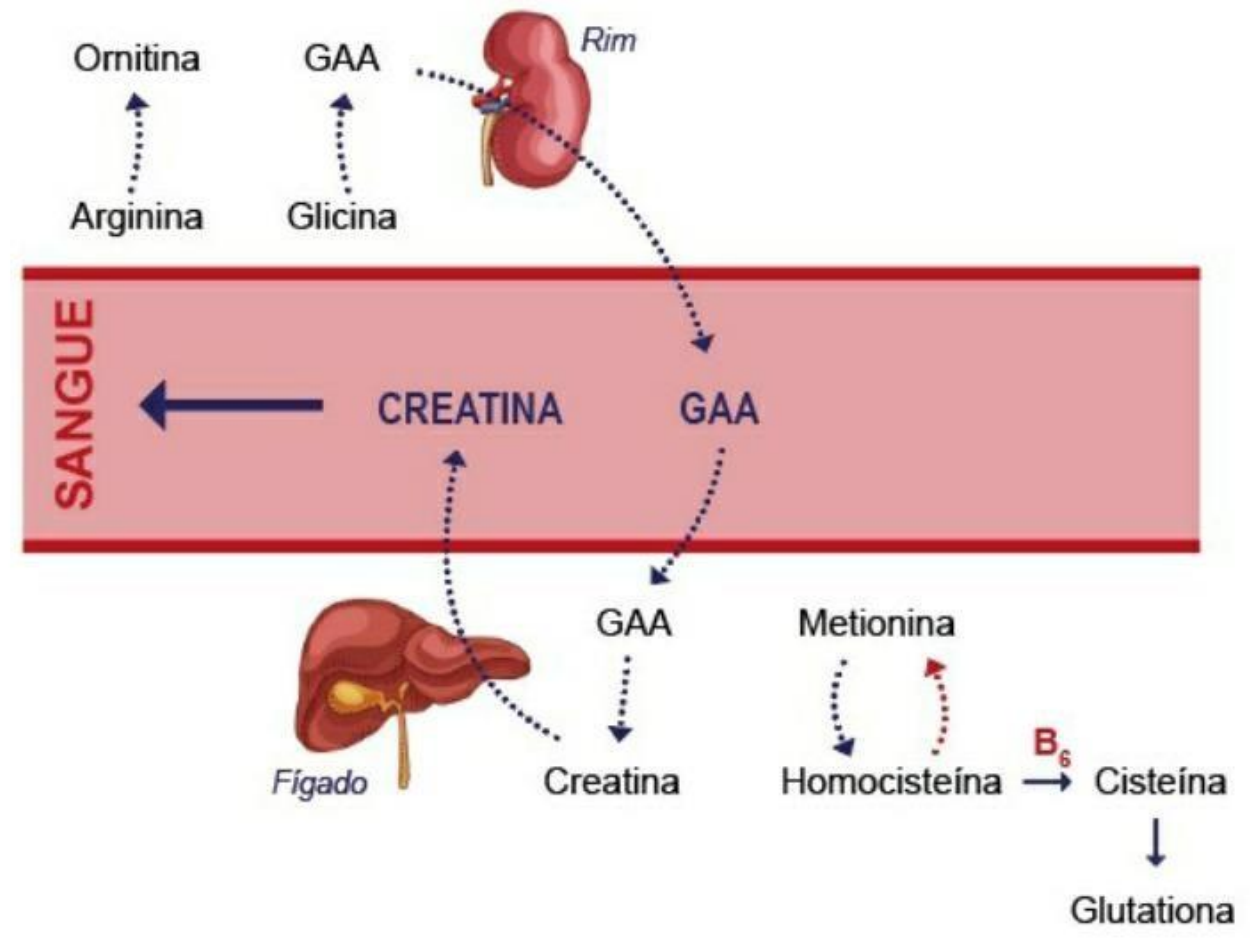

Fonte. Elaboração própria 
A absorção da CR ocorre por conta de um processo saturável de transporte de sódio depende, dependente de uma proteína para que aconteça a translocação da CR do meio extracelular para o intracelular, que ocorre contra o gradiente de concentração. Esta proteína - chamada de CreaT é encontrada em duas isoformas: a CreaT1 e a CreaT2, pertencentes a uma família de transportadores de neurotransmissores dependentes de sódio ( $\mathrm{Na}+$ ) e/ou cloro (Cl-), denominada de solute carrier family - SLC6, com estequeometria de $2 \mathrm{Na}+$ e $1 \mathrm{Cl}$ - por molécula de CR transportada, utilizando a energia do gradiente eletroquímico do $\mathrm{Na}+$ gerado no transporte realizado por outra proteína transportadora, a bomba sódio/potássio ( $\mathrm{Na}+/ \mathrm{K}+\mathrm{ATPase})$. A CreaT1 ou solute carrier class 6 , member 8 (SLC6A8) é considerada o principal transportador de creatina, por isso é denominado simplesmente por CreaT, encontrada no músculo esquelético, cérebro, miocárdio, rins, fígado, pulmões, enterócitos, retina e eritrócitos. A CreaT2 ou solute carrier family 6, member 10 (SLC6A10) é encontrada apenas nos testículos (Guimbal; Kilimann., 1993).

Dentro da célula a CR é fosforilada a CP pela enzima creatina quinase (CK), que terá como funções criar uma reserva energética disponível a qualquer momento, prevenir aumento de adenosina difosfato (ADP) livre intracelular, criar reservatório de prótons, participar da sinalização da glicogenólise, etc (Silva; Bracht, 2001).

No músculo esquelético existe um equilíbrio reversível entre a CR e CP. Na condição de repouso, aproximadamente dois terços do conteúdo de CR está na forma CP. Uma vez que a concentração atinge o seu limiar (150-160 mmol/Kg de músculo) tanto a CR como a CP podem ser degradadas espontaneamente, sofrendo reações irreversíveis de ciclização e desidratação, tendo como resultado a creatinina que, em função de seu caráter não-iônico, se difunde para o meio extracelular e corrente sanguínea, e será transportada para os rins para eliminação na urina (Balsom; Soderlund; Ekblom, 1994). Em um indivíduo saudável a degradação da CR é cerca de 1 a $2 \mathrm{~g}$ por dia, de forma a manter a concentração muscular constante, e a concentração plasmática de creatinina é pequena, entre 50 e 100 mmol/L (Peralta; Amancio, 2002).

\section{Mecanismos de ação}

A energia necessária para realização de atividades pode ser obtida por três sistemas metabólicos: dois anaeróbios (alático e lático) e um aeróbio - sistema aeróbio. Os três sistemas podem operar de forma isolada ou simultânea, dependendo das condições de esforço (intensidade), sendo relativa a contribuição de cada um dos sistemas. A contração muscular necessita da hidrólise do ATP em ADP mais fosfato inorgânico (PI), onde a enzima miosina ATPase é responsável por esta reação, conforme ilustrado na Figura 2. Entretanto, por ser uma molécula de grande peso molecular, apenas $85 \mathrm{~g}$ aproximadamente de ATP são estocados no organismo, sendo necessária a 
constantemente ressíntese de ATP para fornecer toda energia necessária para o trabalho biológico (Mendes; Tirapegui, 2002; Peralta; Amancio, 2002).

Figura 2. Hidrólise de ATP durante atividade muscular
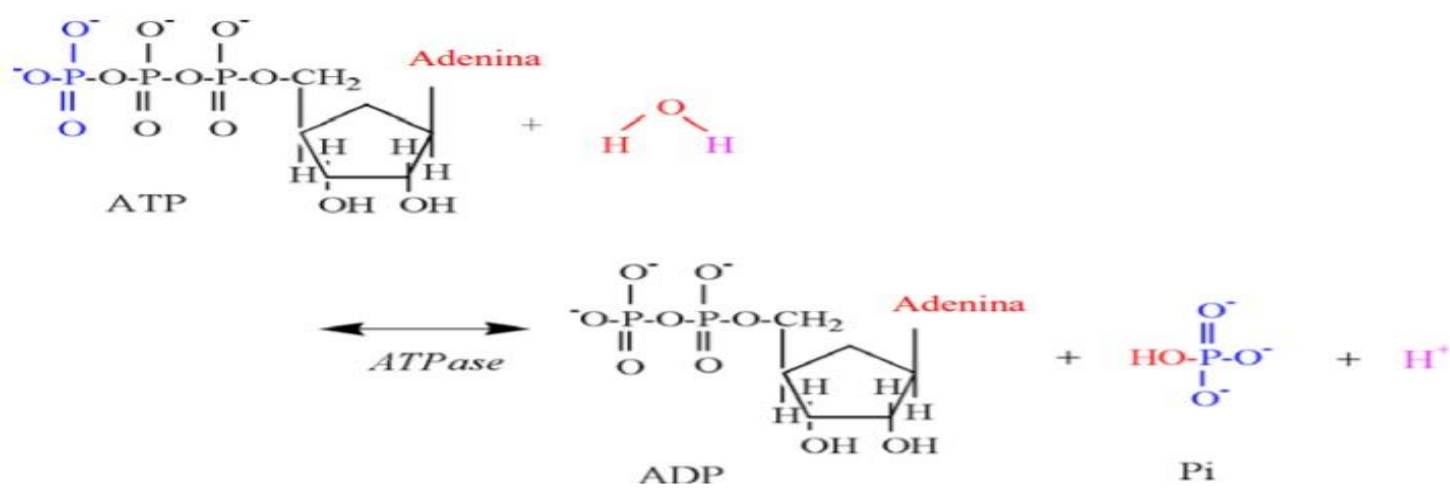

Fonte. Cidade e Talá (2003).

ADP

Em alta intensidade e após a utilização dos estoques de ATP, a primeira parte desta energia é obtida diretamente pelo sistema alático, também conhecido como trifosfato de adenosina creatina fosfato (ATP-CP), fundamental na determinação da capacidade de geração e sustentação de energia em atividades intensas (Mendes; Tirapegui, 2002). Com relação ao tempo de produção de energia por este sistema, a literatura descreve variações entre 3 e 12 segundos (Peralta; Amancio, 2002) até 30 segundos (Mendes; Tirapegui, 2002). A enzima $C K$ age hidrolisando a $C P$, onde ocorre inicialmente a transferência de um grupo fosfato (P) da CP para a molécula de ADP, formando ATP (Peralta; Amancio, 2002). Esta reação permite a imediata reposição de ATP no citosol da célula, como ilustrado na Figura 3.

Figura 3. Ressíntese de ATP por intermédio da fosfocreatina.
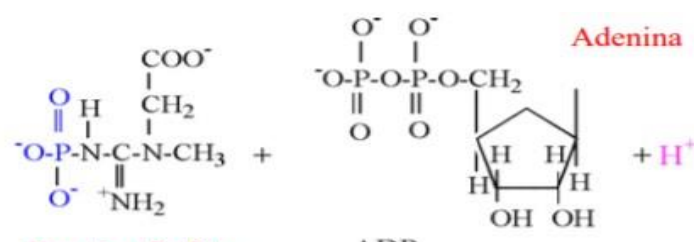

Creatina fosfato

ADP
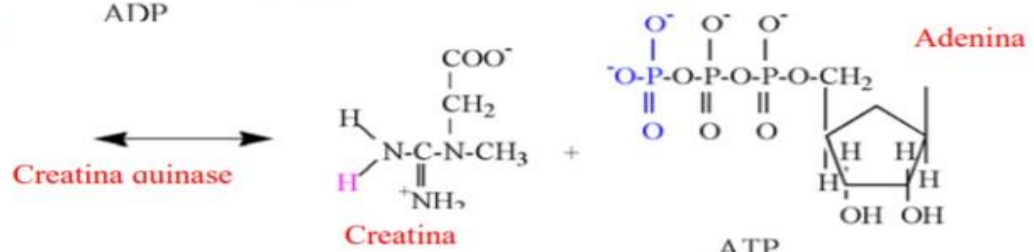

ATP

Fonte. Cidade e Talá (2003) 


\section{Efeitos ergogênicos da suplementação de creatina}

Como visto anteriormente, durante a prática de exercícios de alta intensidade a oferta constante de ATP é primordial para o rendimento, e a CP é a primeira fornecedora de substrato para ressíntese do ATP. Dessa forma, quanto mais a CP é mobilizada para produção de energia, mais os estoques vão diminuindo, dificultando a ressíntese do ATP por este sistema (Peralta; Amancio, 2002). A suplementação de CR se mostra efetiva no processo de conservação de níveis elevados de CP para ressíntese de ATP durante exercícios de alta intensidade (Lanhers et al., 2017). Araújo, Ribeiro e Carvalho (2009) apontam dois importantes efeitos ergogênicos da suplementação de CR: aumento de força e aumento de massa corporal.

Segundo Aoki (2004) a suplementação de CR aumenta o desempenho em alta intensidade e curta duração, como em treinos de força, e descreve que dentre as muitas variáveis que influenciam neste processo o tempo de recuperação entre as séries parece ser 0 efeito ergogênico da CR. A fadiga no exercício de força ocorre por depleção de CP, acidose intramuscular e/ou redução do glicogênio muscular. Considerando que a fadiga pode estar relacionada à redução de $\mathrm{CP}$, a suplementação promove maior conteúdo intramuscular de $\mathrm{CR}$, favorecendo a ressíntese de CP durante o intervalo entre as séries, postergando assim a fadiga por depleção de CP. Gualano et al. (2010, p. 220) descrevem que:

Existem indícios, no entanto, que mesmo na ausência de treinamento de força, a suplementação de creatina poderia ter um efeito benéfico na força muscular, mediado por diversos mecanismos, tais como: I) aumento dos conteúdos intramusculares de fosforilcreatina; II) aumento da velocidade de regeneração de fosforilcreatina durante o exercício; III) melhora na atividade da via glicolítica pelo tamponamento de ions $\mathrm{H+}$; IV) diminuição do tempo de relaxamento no processo contraçãorelaxamento da musculatura esquelética, em decorrência da melhora na atividade da bomba sarcoendoplasmática de cálcio; e V) aumento da concentração de glicogênio muscular. Comparados aos demais, os dois primeiros fatores são aqueles que, teoricamente, mais explicariam a melhora aguda de desempenho.

Entretanto, os trabalhos que descrevem os efeitos sem o treinamento de força possuem vieses como variabilidade individual na resposta à suplementação, falta do controle alimentar, além do baixo poder estatístico. Logo, a combinação da suplementação ao treinamento é mais eficaz para o aumento de força muscular (Gualano et al., 2010).

Mecanismos fisiológicos podem explicar o aumento da musculatura com a suplementação de CR aliada ao treinamento de força. 0 aumento no volume total de água corporal foi uma das primeiras evidências em relação à suplementação de CR. Acreditava-se que a retenção hídrica era a explicação para o ganho de massa magra e peso corporal pelo uso dessa suplementação, porém, tem sido especulado que mudanças nos conteúdos intracelulares de água possam influenciar a tradução de proteínas contráteis, restando saber até que ponto a suplementação de CR é capaz de alterar o balanço hídrico, osmolaridade celular e o balanço proteico (Gualano et al., 2010). Outra explicação é que a suplementação de CR parece ter grande efeito sobre o aumento no volume de 
treinamento. Consequente ao aumento no volume, ocorre melhora na performance, o que pode gerar maior ganho de massa (Syrotuik et al., 2000).

Em modelos animais, foi observado que a suplementação de CR pode atenuar os efeitos de corticosteroides na atrofia muscular. A indução de atrofia por corticosteroides ainda não é completamente compreendida, mas pode envolver a diminuição de expressão do IGF-1 (MENEZES et al., 2007). Mais uma hipótese apontada na literatura é que a suplementação de CR eleva a expressão de genes envolvidos na regulação osmótica, síntese e degradação de glicogênio, remodelagem do citoesqueleto, proliferação e diferenciação de células satélites, reparo e replicação de DNA, controle da transcrição de RNA e morte celular. A CR poderia atuar em vias intracelulares que antecedem os processos de síntese proteica. A suplementação aumentaria a expressão de IGF-1 muscular, que é um ativador de vias na mTOR, tais como PI3K-AKT/PKB. Depois de ativado, o complexo mTOR fosforila o fator de iniciação eucariótico 4E (elF4E) binding protein (4E-BP1) e a P70 ribosomal S6 quinase (p70s6k), promovendo a síntese proteica (Fortes; Curi, 2013), conforme ilustra a Figura 4.

Figura 4. Mecanismo de ação de síntese proteica pela IGF-1

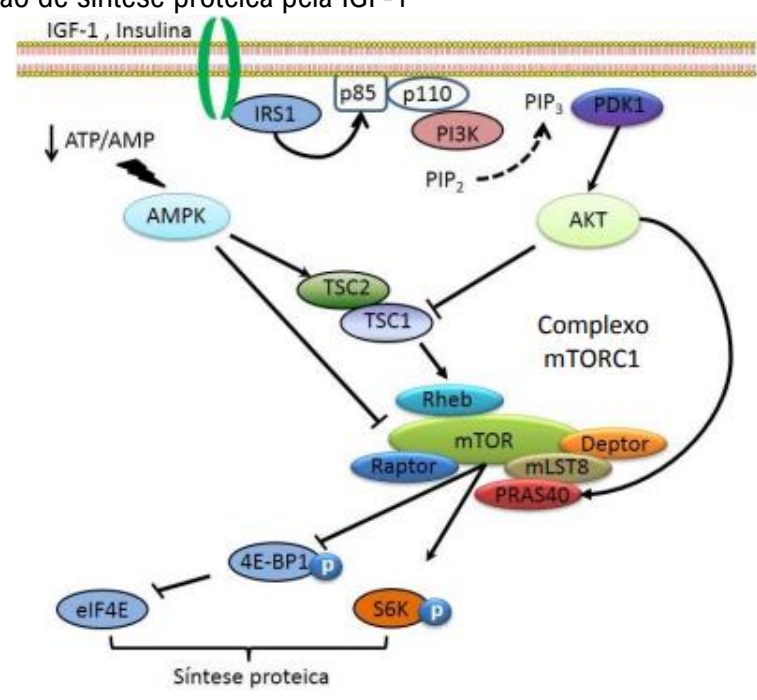

Fonte. Adaptado de Fortes e Curi (2013)

Uma outra explicação para o aumento da massa muscular com a suplementação de CR é 0 aumento de fatores miogênicos regulatórios, essenciais para hipertrofia. 0 treinamento de força combinado com suplementação de CR tem o poder de aumentar a expressão de fatores miogênicos regulatórios, mais especificamente na expressão de fatores regulatórios de miogênese do tipo 4 (MRF4), responsáveis em partes pela proliferação e diferenciação de células satélites. 0 núcleo da fibra muscular adulta não é capaz de sofrer mitoses, porém, existe a necessidade de aumento de mionúcleos para o processo de hipertrofia. 0 binômio treinamento de força e suplementação de CR aumenta a expressão 
de fatores miogênicos regulatórios, que aumentam a proliferação e diferenciação de células satélites. Essas células satélites doam seus mionúcleos à fibra muscular, possibilitando a continuidade do processo de hipertrofia (Willoughby; Rosene, 2003; Gualano et al., 2010).

Exercícios de força e potência são beneficiados com a suplementação de CR, além das atividades de curta duração e alta intensidade (Lanhers et al., 2017; Confortin et al, 2019). A suplementação de CR pode ser realizada por duas maneiras que incluem uma fase de sobrecarga, com ingestão de 20 a $25 \mathrm{~g}$ (ou 0,3 g/ $/ \mathrm{kg}$ ) por 5 até 7 dias, seguido pela fase de manutenção, com ingestão ente 3 a $5 \mathrm{~g}$ (ou $0,03 \mathrm{~g} / \mathrm{kg}$ ) por dia, enfatizando que a sobrecarga não é necessária para todos os indivíduos (Naderi et al., 2016). Antigamente muito se falava sobre o período de washout, que é um período compreendido por quatro semanas sem a suplementação da creatina, para que os estoques musculares voltassem aos níveis basais (Nemezio; Oliveira; Silva, 2015). Porém, já se sabe que esta prática não é mais necessária, sendo indicada a suplementação em dosagem de manutenção de forma contínua (Naderi et al., 2016). 0 quadro 2 é composto por um compilado de estudos controlados, que demonstram a efetividade da suplementação de CR na mudança da composição corporal e no aumento do desempenho na prática de exercícios resistidos.

Quadro 2. Compilado de estudos controlados sobre os efeitos da suplementação de creatina.

\begin{tabular}{|c|c|c|}
\hline Autor e ano & Posologia & Principais resultados \\
\hline Vandenberghe et al. (1997) & $\begin{array}{l}20 \mathrm{~g} \text { de CR por } 4 \text { dias } \\
+5 \mathrm{~g} \text { de CR por } 10 \\
\text { semanas. }\end{array}$ & $\begin{array}{l}+5,8 \% \text { massa magra; +56,2\% 1RM extensão } \\
\text { joelho; }+45,6 \% \text { 1RM agachamento; }+42,6 \% 1 \mathrm{RM} \\
\text { leg press; }+3 \% \text { massa corporal total*; }+44,7 \% \\
\text { 1RM supino*; +63\% 1RM flexão joelho* e }+30,7 \% \\
\text { desenvolvimento*. }\end{array}$ \\
\hline Volek et al. (1999) & $\begin{array}{l}25 \mathrm{~g} / \text { dia de CR por } 7 \\
\text { dias }+5 \mathrm{~g} / \text { dia de } \text { CR } \\
\text { por } 12 \text { semanas. }\end{array}$ & $\begin{array}{l}+6,3 \% \text { massa corporal total; }+6,3 \% \text { massa magra; } \\
+24 \% 1 \mathrm{RM} \text { supino e }+32 \% 1 \mathrm{RM} \text { agachamento. }\end{array}$ \\
\hline Chrusch et al. (2001) & $\begin{array}{l}0,3 \mathrm{~g} / \mathrm{kg} \text { de } \mathrm{CR} \text { por } 5 \\
\text { dias. }\end{array}$ & $\begin{array}{l}+3,4 \% \text { massa corporal total; }+6 \% \text { massa magra; } \\
+36,8 \% 1 \mathrm{RM} \text { leg press; }+51,7 \% 1 \mathrm{RM} \text { extensão } \\
\text { perna e }+27,2 \% 1 \mathrm{RM} \text { supino* }\end{array}$ \\
\hline Jowko et al. (2001) & $\begin{array}{l}\text { 20g/dia de por } 7 \text { dias } \\
+10 \mathrm{~g} \text { de CR por } 3 \\
\text { semanas. }\end{array}$ & $\begin{array}{l}+2,6 \% \text { massa corporal total; }+2,8 \% \text { massa magra; } \\
+13,7 \% 1 \mathrm{RM} \text { agachamento; }+13,8 \% \text { 1RM flexão } \\
\text { de cotovelo; }+16,5 \% 1 \mathrm{RM} \text { extensão de cotovelo e } \\
+1,4 \% 1 \mathrm{RM} \text { supino*. }\end{array}$ \\
\hline Aoki (2004) & $\begin{array}{l}20 \mathrm{~g} \text { de } \text { CR por } 5 \text { dias } \\
+2 g \text { de CR por } 7 \\
\text { dias. }\end{array}$ & $\begin{array}{l}\text { Aumento da capacidade de repetição máxima } \\
\text { com intervalo de } 2 \text { minutos e } 30 \text { segundos. }\end{array}$ \\
\hline Cribb e Hayes (2006) & $\begin{array}{l}0,07 \mathrm{~g} / \mathrm{kg} / \mathrm{dia} \text { de } \mathrm{CR} \\
\text { nos dias de } \\
\text { treinamento. }\end{array}$ & $\begin{array}{l}+3 \% \text { massa corporal total; }+4 \% \text { massa magra; } \\
+14,1 \% 1 \mathrm{RM} \text { agachamento; }+9,6 \% 1 \mathrm{RM} \text { supino } \mathrm{e} \\
+12,3 \% 1 \mathrm{RM} \text { levantamento terra*. }\end{array}$ \\
\hline
\end{tabular}




\begin{tabular}{|c|c|c|}
\hline $\begin{array}{l}\text { Cribb, Williams e Hayes } \\
(2007 a)\end{array}$ & $\begin{array}{l}0,3 \mathrm{~g} / \mathrm{kg} / \mathrm{dia} \text { de } \mathrm{CR} \\
\text { por } 1 \text { semana }+ \\
0,1 \mathrm{~g} / \mathrm{kg} / \mathrm{dia} \text { por } 10 \\
\text { semanas. }\end{array}$ & $\begin{array}{l}+4,7 \% \text { massa corporal total }{ }^{*} ;+6,4 \% \text { massa magra; } \\
+25 \% 1 \mathrm{RM} \text { agachamento; }+19 \% 1 \mathrm{RM} \text { supino } \mathrm{e} \\
+16,6 \% 1 \mathrm{RM} \text { pulley. }\end{array}$ \\
\hline $\begin{array}{l}\text { Cribb, Williams e } \mathrm{Ha} \\
(2007 \mathrm{~b})\end{array}$ & $\begin{array}{l}0,1 \mathrm{~g} / \mathrm{kg} / \mathrm{dia} \text { de } \mathrm{CR} \\
\text { por } 10 \text { semanas. }\end{array}$ & $\begin{array}{l}+7,9 \% \text { massa corporal total }{ }^{*} ;+9,9 \% \text { massa magra; } \\
+28,4 \% 1 \mathrm{RM} \text { agachamento; }+20,7 \% 1 \mathrm{RM} \text { supino } \\
\text { e }+17,2 \% 1 \mathrm{RM} \text { pulley. }\end{array}$ \\
\hline Kerksick et al. (2007) & $\begin{array}{l}3 \mathrm{~g} / \text { dia de por } 12 \\
\text { semanas. }\end{array}$ & $\begin{array}{l}+2,2 \% \text { massa corporal total; }+2,8 \% \text { massa magra; } \\
+7,3 \% 1 \mathrm{RM} \text { supino* e }+11,5 \% 1 \mathrm{RM} \text { leg press }{ }^{*}\end{array}$ \\
\hline Candow et al. (2008) & $\begin{array}{l}0,1 \mathrm{~g} / \mathrm{kg} \text { de } \mathrm{CR} \text { em } \\
\text { dias de treino. }\end{array}$ & $\begin{array}{l}+0,8 \% \text { massa corporal total; }+2,2 \% \text { massa } \\
\text { magra*; }+12 \% 1 \mathrm{RM} \text { supino* }{ }^{*}+12 \% 1 \mathrm{RM} \text { leg } \\
\text { press }^{*} \text {. }\end{array}$ \\
\hline
\end{tabular}

* sem alterações significativas em relação ao grupo controle.

Existe uma questão bem pertinente sobre como ingerir a creatina: antes ou após o treino. Como o objetivo é realizar fornecimento para saturação e/ou manutenção das doses, 0 momento de ingestão é indiferente. 0 que se sabe de fato é que a suplementação de creatina concomitante com carboidrato e proteína promove um aumento significante nos níveis totais de creatina, creatina livre e fosfocreatina, provavelmente por efeito positivo na liberação de insulina e retenção de creatina (Farah; Santos, 2002).

Sobre os possíveis efeitos colaterais, em pessoas saudáveis uma leve elevação na concentração plasmática de $\mathrm{CR}$, a princípio, não seria prejudicial para a saúde. 0 que existe é um relato na literatura de um homem com esclerose glomerular segmentar, que apresentou aumento da creatina no plasma e redução na taxa de filtração renal glomerular após o início da suplementação de creatina, sendo que essas alterações foram sanadas com um mês após o término da suplementação. Dessa forma, em pessoas com alguma disfunção renal pré-existente, recomenda-se cautela com a suplementação, e que não seja realizada nenhuma suplementação sem a devida supervisão profissional (Sousa; Azevedo, 2008).

\section{CONSIDERAÇÕES FINAIS}

De acordo com os achados ficam claras as evidências quanto aos benefícios da suplementação com a creatina para fins de performance e ganho de massa muscular para praticantes de exercícios, especialmente aqueles de alta intensidade e curta duração. A creatina atua em uma das vias metabólicas de fornecimento e reposição de energia, via alática, possibilitando assim que o indivíduo aumente o rendimento no treino, as repetições, a força durante o período final do exercício por postergar o surgimento da 
fadiga. Além disso, o aumento no volume de água nas células musculares, estímulo para 0 aumento de síntese proteica, aumento na expressão gênica de IGF-1 e o aumento de fatores miogênicos regulatórios são fatores que podem levar a uma melhora na adaptação muscular e o desenvolvimento de massa magra.

Sobre a forma de utilização, existem duas opções de posologia recomendadas: a primeira envolve uma fase de sobrecarga, onde é realizada a ingestão de 20 a $25 \mathrm{~g}$ (ou 0,3 g/kg) por 5 até 7 dias, seguido pela fase de manutenção, com ingestão ente 3 a $5 \mathrm{~g}$ (ou 0,03 $\mathrm{g} / \mathrm{kg}$ ) por dia. A segunda opção recomendada seria sem a fase de sobrecarga, iniciando com a dosagem de manutenção e mantendo a mesma, desta forma levaria um tempo maior para atingir o pico na concentração de CR no organismo.

Quanto aos possíveis riscos de sua utilização, a revisão aponta uma suplementação segura para pessoas saudáveis e não está associada a nenhuma complicação. Para os indivíduos que possuem alguma disfunção renal pré-existente, recomenda-se cautela com a suplementação, e que não seja realizada nenhuma suplementação sem a devida supervisão profissional. 


\section{BIBLIOGRAFIA}

Aoki, M. S. (2004). Suplementação de creatina e treinamento de força: efeito do tempo de recuperação entre as séries. Revista Brasileira de Ciência e Movimento, 12(4), 39-44.

Araujo, E. R., Ribeiro, P. S., Carvalho, S. F. D. (2009). Creatina: metabolismo e efeitos de sua suplementação sobre o treinamento de força e composição corporal. Revista Brasileira de Nutrição Esportiva, 3(13), 63-69.

Balsom, P., Soderlund, K., Ekblom, B. (1994). Creatine in humans with special reference to creatine supplementation. Sports Medicine, 18(4), 268-280.

Brasil. (2010). Ministério da Saúde. Biblioteca Virtual em Saúde do Ministério da Saúde. Resolução - RDC no 18, de 27 de abril de 2010. Dispõe sobre alimentos para atletas. Brasília: Diário Oficial da República Federativa do Brasil. Acesso em 10 de jul. 2021.

Candow, D. G. et al. (2008). Low-Dose Creatine Combined with Protein during Resistance Training in Older Men. Medicine \& Science in Sports \& Exercise, 40(9), 1645-1652.

Cidade, L. M., Talá, E. M. (2003). A validade da suplementação de creatina e suas limitações. $41 \mathrm{f}$. Monografia (curso de especialização lato-sensu de Qualidade em Alimentos) - Universidade de Brasília, 2003.

Confortin, F. G. et al. (2019). Efeito ergogênico da creatina sobre a performance de atletas do Handebol. Revista Brasileira de Nutrição Esportiva, 13(78), 254-264.

Cribb, P. J., Hayes, A. (2006). Effects of Supplement Timing and Resistance Exercise on Skeletal Muscle Hypertrophy. Medicine \& Science in Sports \& Exercise, 38(11), 1918-1925.

Cribb, P. J. et al. (2007a). Effects of Whey Isolate, Creatine, and Resistance Training on Muscle Hypertrophy. Medicine \& Science in Sports \& Exercise, 39(2), 298-307.

Cribb, P. J., Williams, A. D., Hayes, A. (2007b). A Creatine-Protein-Carbohydrate Supplement Enhances Responses to Resistance Training. Medicine \& Science in Sports \& Exercise, 39(11), 1960-1968.

Chrusch, M. J. et al. (2001). Creatine supplementation combined with resistance training in older men. Medicine \& Science in Sports \& Exercise, 33(12), 2111-2117.

Farah, J. E., Santos, M. G. (2012). Efeito da suplementação com creatina nos esportes. EFDeportes.com, 17(167), s/p. 
Febbraio, M. A. et al. (1995). Effect of creatine supplementation on intramuscular TCr, metabolism and performance during intermittent, supramaximal exercise in humans. Scandinavian Physiological Society, 155(4), 387-395.

Fortes, M. A. S., Curi, R. (2014). Impacto do diabetes induzido por estreptozotocina na resposta hipertrófica dos músculos sóleo e extensor digital longo (EDL). Dissertação de Mestrado. 110 f. Dissertação (Programa de Pós-graduação em Fisiologia Humana). Instituto de Ciências Biomédicas - Universidade de São Paulo, USP: São Paulo, 2014.

Gomes, M. R., Tirapegui, J. (2000). Relação de alguns suplementos nutricionais e 0 desempenho físico. Archivos Latinoamericanos de Nutrición, 50(4), 317-329.

Gualano, B. et al. (2010). Efeitos da suplementação de creatina sobre força e hipertrofia muscular: atualizações. Revista Brasileira de Medicina do Esporte, 16(3), 219-223.

Guimbal, C., Kilimann, M. W. (1993). Na(+)-dependent creatine transporter in rabbit brain, muscle, heart, and kidney. cDNA cloning and functional expression. Journal of Biological Chemistry, 268(12), 8418-8421.

Jówko, E. et al. (2001). Creatine and $\beta$-hydroxy- $\beta$-methylbutyrate (HMB) additively increase lean body mass and muscle strength during a weight-training program. Nutrition, 17(7), 558-566.

Kerksick, C. M. et al. (2007). Impact of differing protein sources and a creatine containing nutritional formula after 12 weeks of resistance training. Nutrition, 23(9), 647-656.

Lanhers, C. et al. (2017). Creatine Supplementation and Upper Limb Strength Performance: A Systematic Review and Meta-Analysis. Sports Medicine, 47(1), 163173.

Mendes, R., Tirapegui, J. (2002). Creatina: o suplemento nutricional para a atividade física - Conceitos atuais. Archivos Latinoamericanos de Nutrición, 52(2), 117-127.

Menezes, L. G. et al. (2007). Creatine supplementation attenuates corticosteroid-induced muscle wasting and impairment of exercise performance in rats. Journal of Applied Physiology, 102(2), 698-703.

Naderi, A. et al. (2016). Timing, optimal dose and intake duration of dietary supplements with evidence-based use in sports nutrition. Journal of Exercise Nutrition \& Biochemistry, 20(4), 1-12.

Nemezio, K. M. A., Oliveira, C. R. C., Silva, A. E. L. (2015). Suplementação de creatina e seus efeitos sobre o desempenho em exercícios contínuos e intermitentes de alta intensidade. Rev. Educ. Fís/UEM, 26(1), 157-165. 
Peralta, J., Amancio, O. M. S. (2002). A creatina como suplemento ergogênico para atletas. Revista de Nutrição, 15(1), 83-93.

Persky, A. M., Brazeau, G. A., Hochhaus, G. (2003). Pharmacokinetics of the Dietary Supplement Creatine. Clinical Pharmacokinetics, 42(6), 557-574.

Silva, E. G. B., Bracht, A. M. K. (2001). Creatina, função energética, metabolismo e suplementação no esporte. Journal of Physical Education, 12(1), 27-33.

Sousa, M. A. Q., Azevedo, C. H. G. (2008). Suplementação de creatina e possíveis efeitos colaterais. Revista Brasileira de Nutrição Esportiva, 2(9), s/p.

Syrotuik, D. G. et al. (2000). Absolute and Relative Strength Performance Following Creatine Monohydrate Supplementation Combined With Periodized Resistance Training. The Journal of Strength \& Conditioning Research, 14(2), 182-190.

Vandenberghe, K. et al. (1997). Long-term creatine intake is beneficial to muscle performance during resistance training. Journal of Applied Physiology, 83(6), 20552063.

Volek, J. S. et al. (1999). Performance and muscle fiber adaptations to creatine supplementation and heavy resistance training. Medicine \& Science in Sports \& Exercise, 31(8), 1147-1156.

Willoughby, D. S., Rosene, J. M. (2003). Effects of Oral Creatine and Resistance Training on Myogenic Regulatory Factor Expression. Medicine \& Science in Sports \& Exercise, 35(6), 923-929. 


\section{JIM}

\section{JORNAL DE INVESTIGAÇÃO MÉDICA}

\section{pontěditora}

